\title{
50 Glorious Years: Celebrating the Future
}

$\mathrm{T}$ he age of 50 years brings to the mind a number of clichés, the foremost of which are 'half-alifetime', 'lessened productivity' or 'the dawn of retreat.' The other factors that come to mind are 'the age of maturity', 'the voice of experience' and 'the peak of one's life.' The casual exclusion of the former ones is surely one of the upside of being a journal. With this issue, the Journal of Indian Academy of Pediatrics heralds its 50th Volume. The editorial board of Indian Pediatrics joins the Academy members, the subscribers, reviewers, and the authors, to celebrate its Golden Jubilee and the golden years that lie ahead. To recollect the past and acknowledge the contribution of all the 50 Presidents of Indian Academy of Pediatrics and 10 Editors of Indian Pediatrics, we are publishing their photographs, within this article. Let's also have a look at what we have achieved in recent years.

\section{Circulation and Submissions}

The circulation of the print version is nearing the 20,000 mark (estimated readership 1,00,000 per month) commensurate with the increasing membership of the Academy (Fig. 1). Increase in print order by more than 3000 in last 5 years has translated into increasing burden of the resources for the journal (manpower, time, money). Despite that we have been able to stick to a tight schedule to ensure that this burden is not passed on to the members, and that they continue to get their print copy

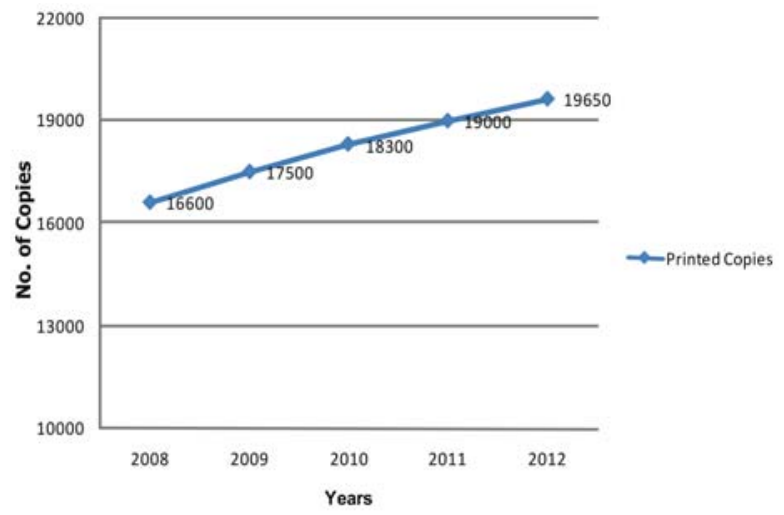

Fig. 1 Monthly circulation of Indian Pediatrics. by the third week of the month, every month without fail. Cambridge Press, who are printing Indian Pediatrics since 1981, deserve a special accolade; we are proud to announce that not once in last 30 years we have missed our posting schedule even by a day.

\section{Measures of Popularity}

Increasing number of submission of manuscripts to any journal is an objective marker of its popularity. In the last 6 years, the submissions have increased from 750 to 1200 per annum; an increase to the tune of more than $50 \%$ (Fig. 2). Inevitably, since the print space is limited, the acceptance rate has decreased, but not at the cost of rejecting good articles. In the last year, we received submissions from 43 countries, from all inhabited continents, across the globe.

Impact factor of any journal is supposed to be another yardstick to measure its popularity [1]. Our first Impact factor released in 2008 was 0.75 . This has increased to 1.048 in 2012; an unparalleled growth of more than $40 \%$ in last 4 years. Among specialty biomedical journals, we are No. 1 in India. Indian Pediatrics enjoys an incredible web presence with its website $w w w$.indianpediatrics.net receiving over 1 million hits per month (Fig. 3). The website is rated as the topmost ranking Pediatric journal website in the world! To top it all, the journal is now accessed by more than 2700 institutions worldwide.

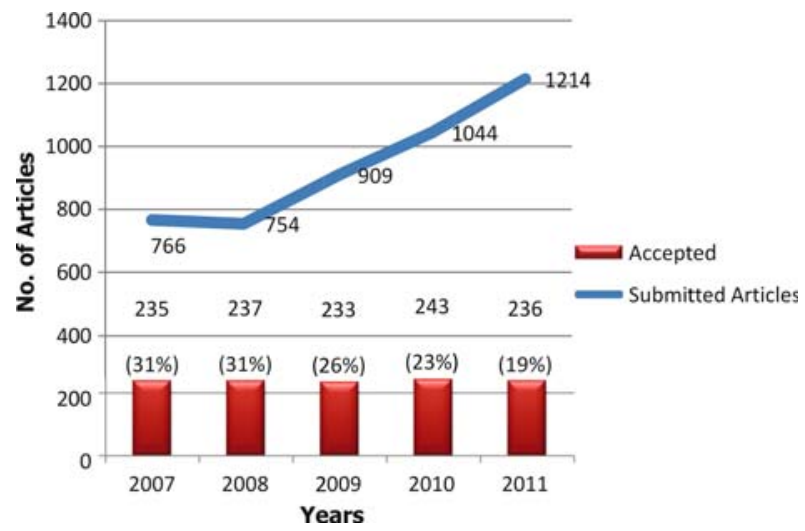

FIG. 2 Manuscripts submitted \& accepted in Indian Pediatrics. 


\section{PRESIDENTS OF IAP}

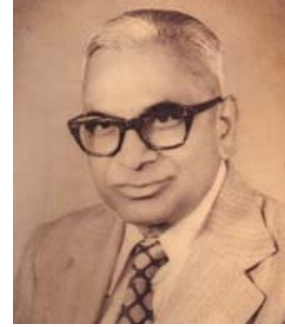

L.S.N. Prasad

(1964)

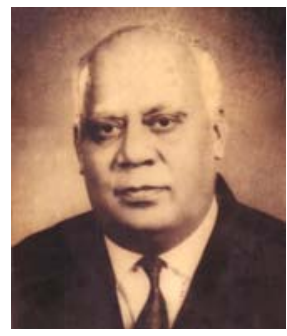

Harish Chandra (1969)

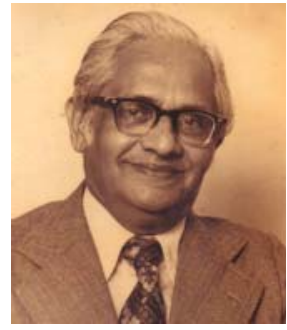

B.D. Patel

(1974)

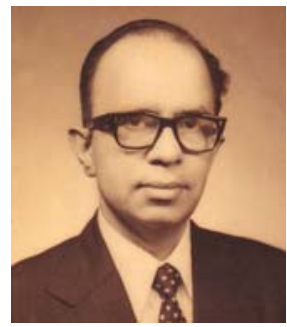

R.K. Gandhi

(1979)

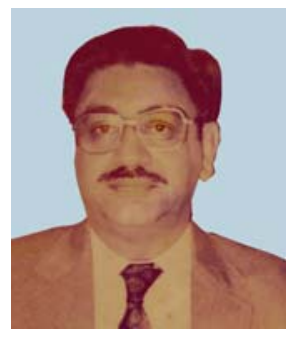

Kanwar K. Kaul

(1984)

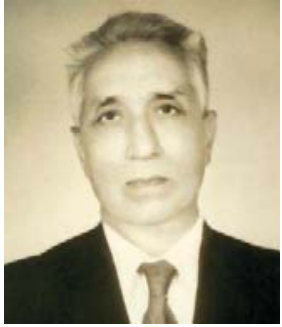

P.N. Taneja

(1965)

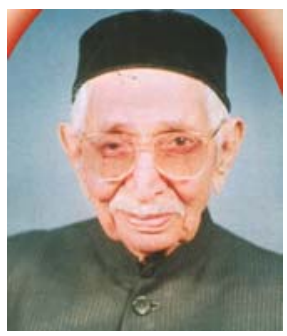

J.N. Pohowalla (1970)

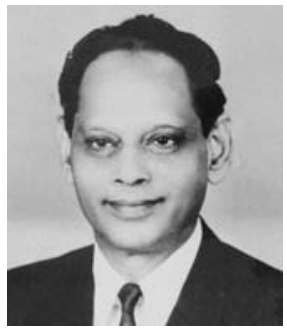

V. B. Raju

(1975)

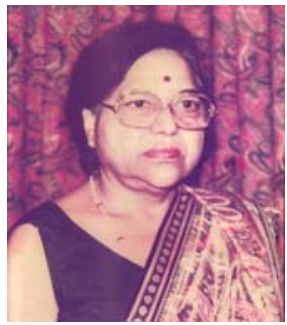

Satya Gupta

(1980)

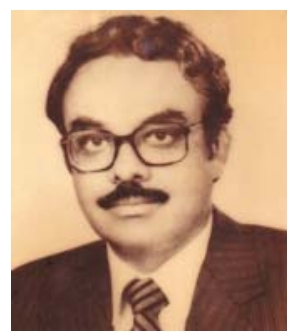

S.K. Bhargava

(1985)

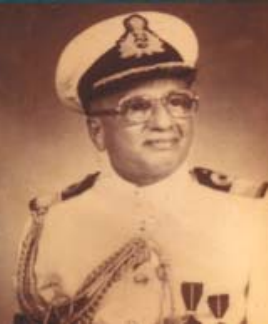

Shantilal C. Sheth

(1966)

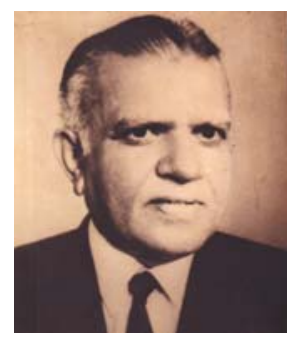

S.M. Merchant

(1971)

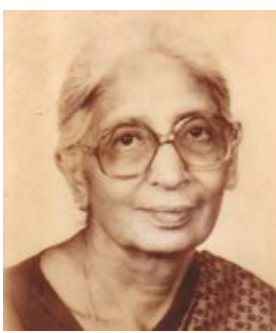

Shanti Ghosh

(1976)

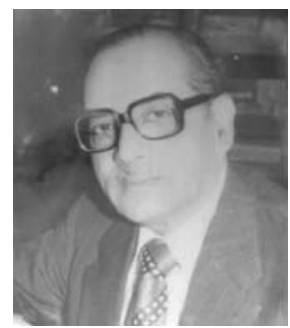

S.P. Ghosal

(1981)

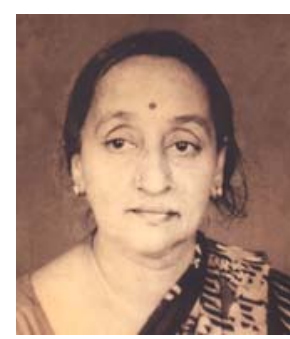

N. Sundaravalli

(1986)

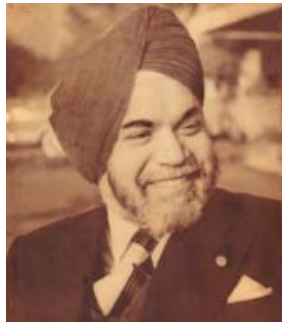

S.S.Manchanda (1967)

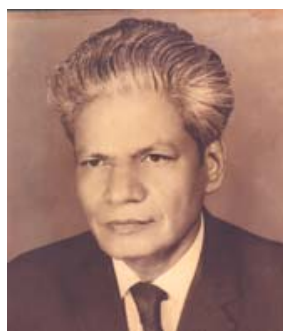

N.S. Tibrewala

(1972)

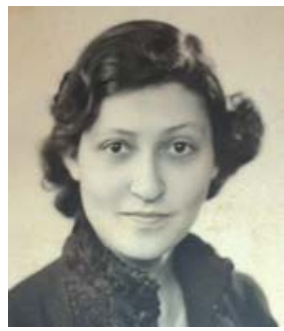

Piloo E. Bharucha (1977)

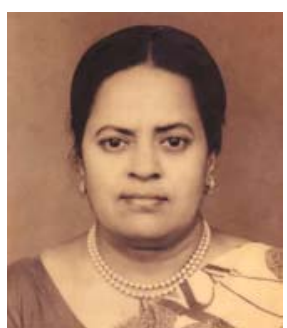

K. Indirabai

(1982)

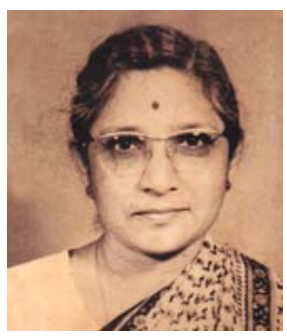

Avalokita B. Desai (1987)

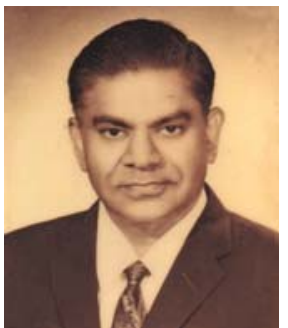

P.M. Udani

(1968)

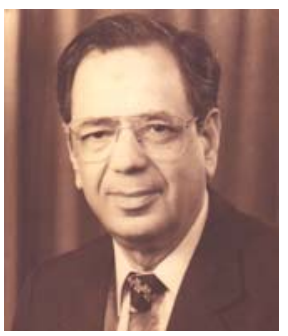

R.S. Dayal

(1973)

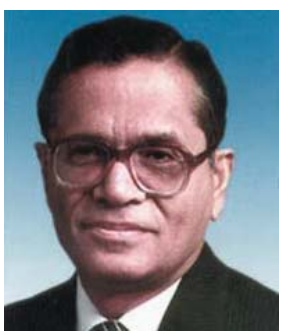

O.P. Ghai

(1978)

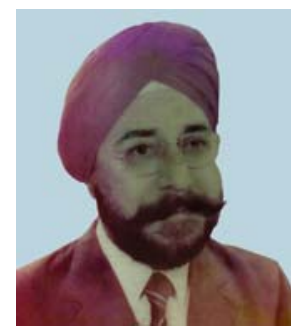

B.N.S. Walia

(1983)

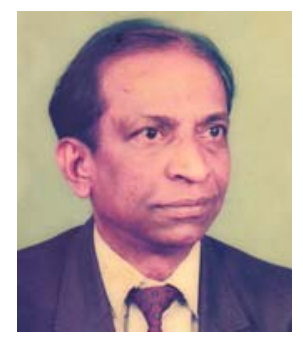

D.G. Benakappa

(1988)

Indian PEDIATRICS 
PRESIDENTS OF IAP

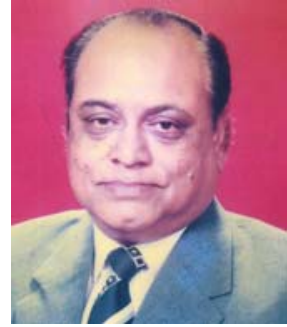

N.R. Bhandari

(1989)

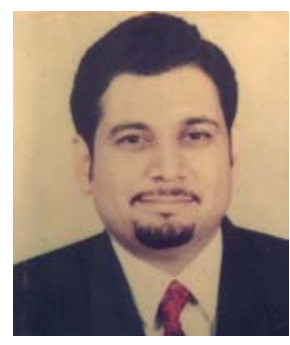

Uday Bodhankar (1994)

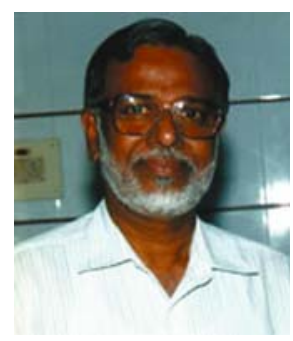

T. Jacob John (1999)

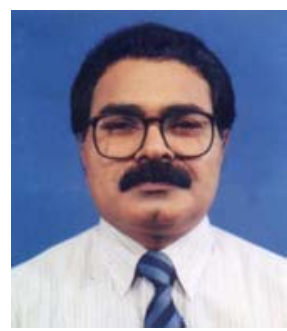

M.K.C. Nair

(2004)

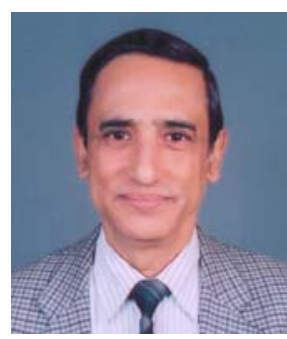

Panna Choudhury (2009)

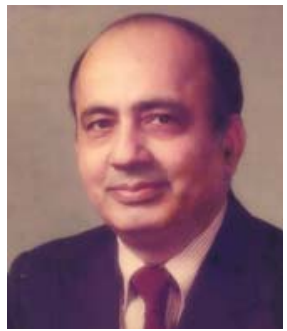

S.C. Arya

(1990)

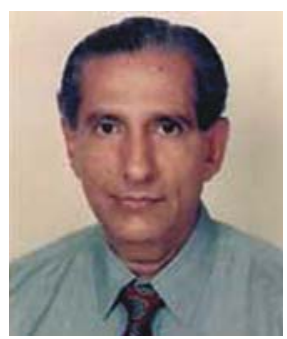

Y.K. Amdekar (1995)

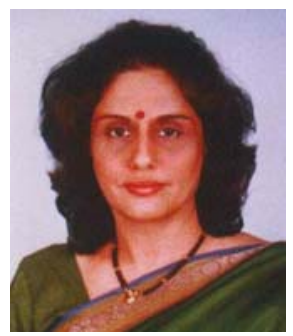

Swati Y. Bhave (2000)

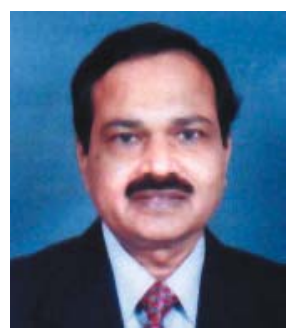

Raju C Shah (2005)

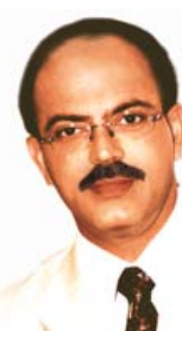

Deepak Ugra (2010)

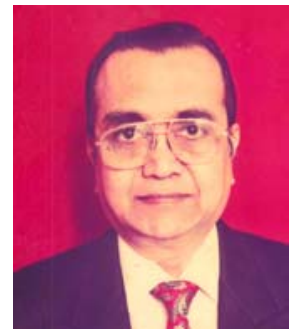

N.B. Kumta

(1991)

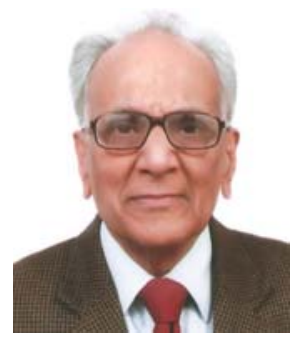

R.N. Srivastava (1996)

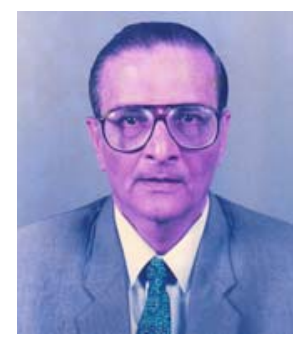

Y.C. Mathur (2001)

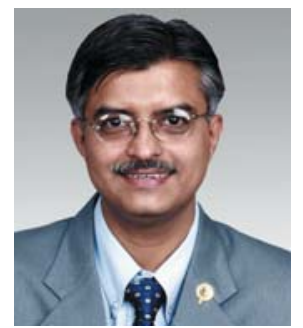

Nitin K. Shah

(2006)

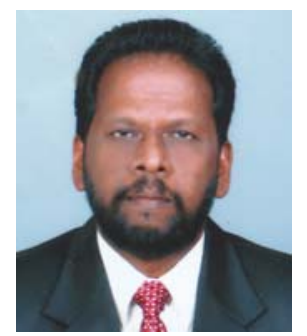

T.U. Sukumaran (2011)

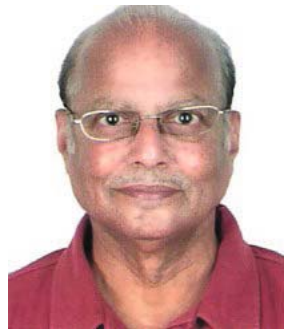

R.D. Potdar

(1992)

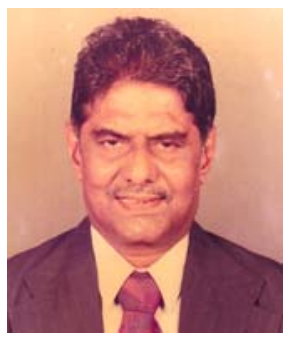

A. Parthasarathy (1997)

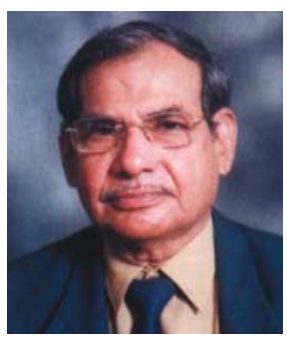

Dilip Mukherjee (2002)

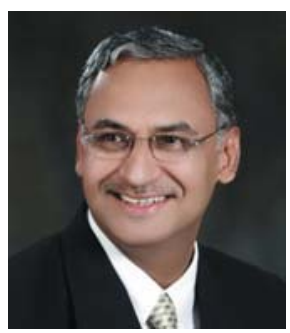

Naveen C. Thacker

(2007)

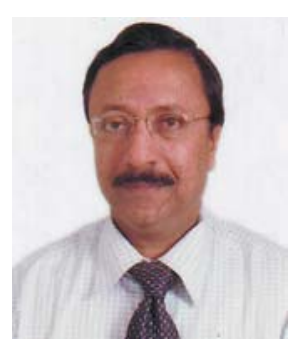

Rohit C. Agrawal

(2012)

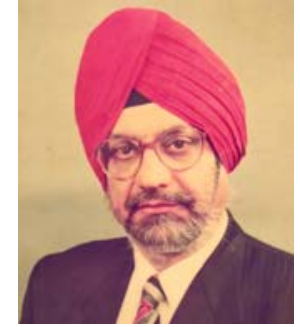

Meharban Singh (1993)

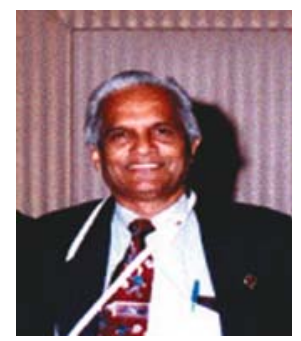

M.R. Lokeshwar (1998)

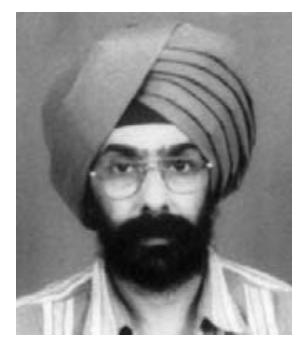

H.P.S. Sachdev (2003)

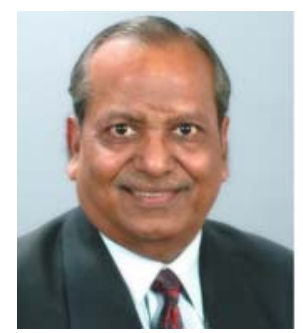

R.K. Agarwal

(2008)

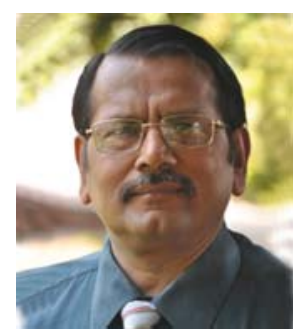

C.P. Bansal

(2013)

INDIAN PEDIATRICS 


\section{CHANGING FACEOF INDIAN PEDIATRICS}

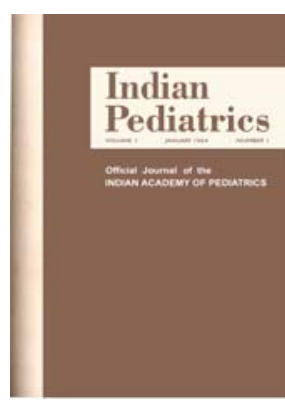

1964

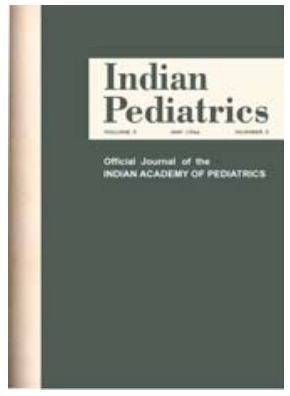

1966

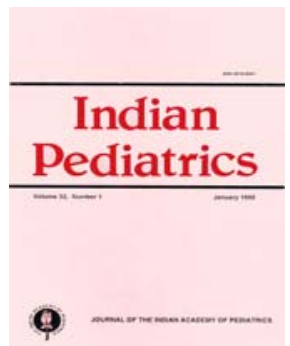

1995

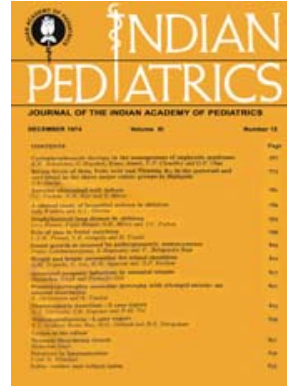

1974

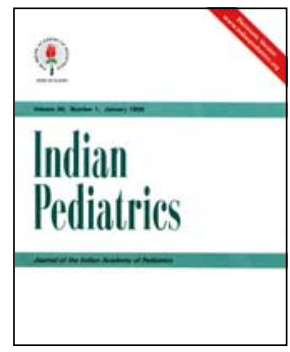

1999

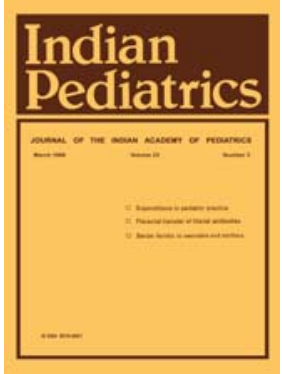

1986

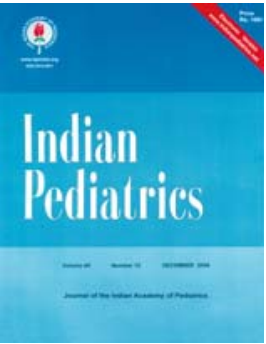

2007

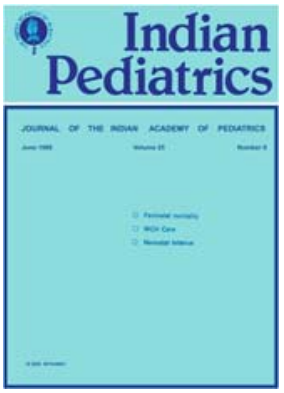

1988

Indian Pediatrics

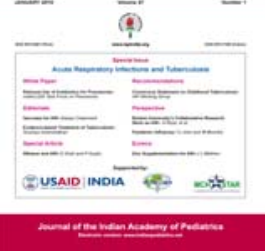

2009

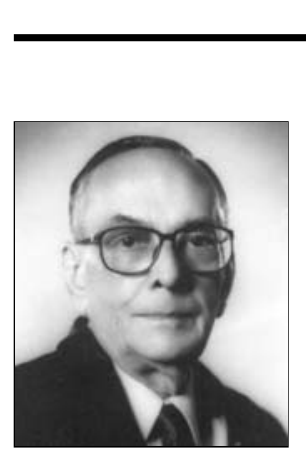

Sisir K. Bose (1964-1966)

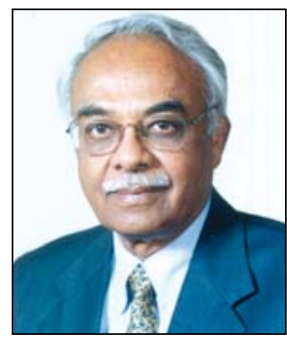

S.K. Bhargava (1980-1984)

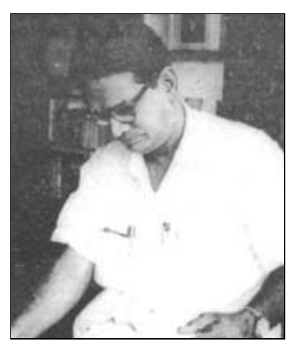

N.G. Mojumdar (1967-1969)

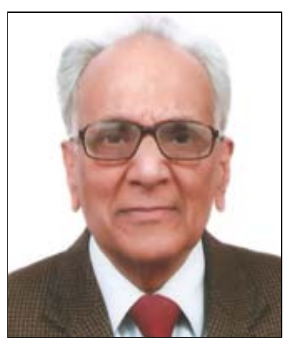

R.N. Srivastava (1985-1990)

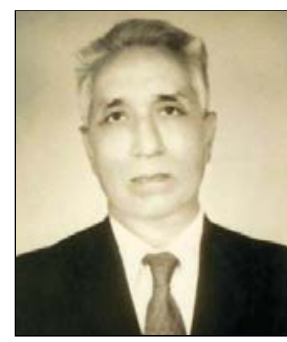

P.N. Taneja (1970-1972)

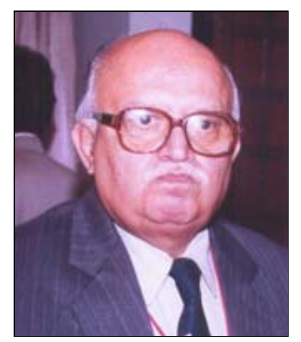

R.K. Puri (1990-1994)

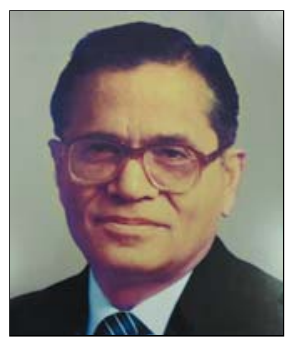

O.P. Ghai

(1973-1975)

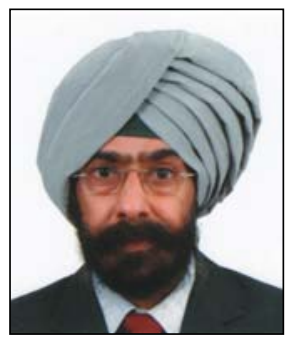

HPS Sachdev (1994-2001)

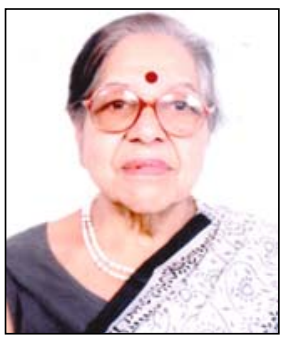

Satya Gupta (1976-1980)

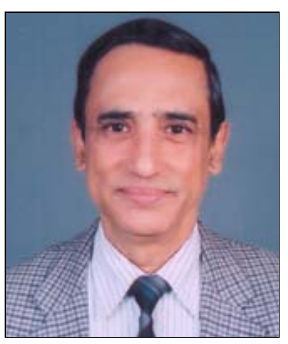

Panna Choudhury (2002-2007) 


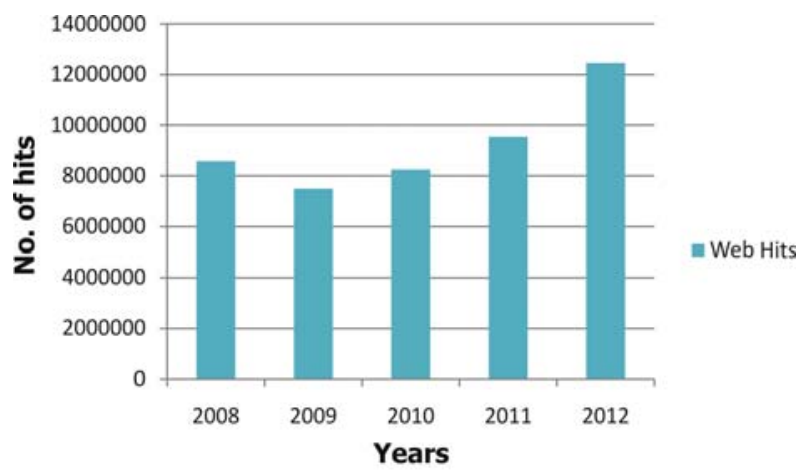

Fig. 3 Number of websites hits per month on www.indianpediatrics.net.

We have completed digitization of all past issues dating back to 1991 with in-house expertise only. Each and every article published since 1991 is now available freely at our website. Our major endeavor in this Golden Jubilee Year is to put up the Table of contents of archival issues (1964 onwards) online. The process has already started with the first ten volumes already available on our website.

We are proud to say that we have kept our promises [2] made to both our readers and the authors, without letting the personal, financial, or other relationships affect our decisions or losing at any time the dignity of editorial independence.

\section{Collaboration with Springer and Online Manuscript Management System}

The international edition of Indian Pediatrics (for overseas distribution) was launched in January 2010. On 19th May 2010, the online manuscript submission, tracking and peer review system "Editorial Manager" was successfully initiated at https:// www.editorialmanager. com/inpe/. The International Edition and Editorial Manager are the result of a unique collaboration with Springer, a global scientific, technical and medical publisher. Springer also hosts Indian Pediatrics on its website and has the exclusive rights to distribute the International edition. However, unlike its contemporaries, the journal continues to host its contents on its website and the open access status of the journal is maintained for authors and readers who can access the journal through www.indianpediatrics.net, which remains fully functional as before with the added link for online submission. Indian Pediatrics can also be accessed through Springer webpage by clicking on to $w w w$. springer.com/medicine/pediatrics/journal/13312 [3].

As of now, Indian Pediatrics has gone totally online with all of the manuscripts being received, peerreviewed and processed through the online manuscript management system. The reviewer base has also widened with the journal now having reviewers from more than 40 countries. The online manuscript management system has enabled faster review times and transparency of workflow, such as the ability to keep track of the manuscript. In the year 2011, average turnaround time for decision (number of days between the date the manuscript was received and the first decision) was only 10.2 days!

To maintain the highest standards of publication ethics besides quality publication, Indian Pediatrics is now also screening the manuscripts for any plagiarized material with software ithenticate, acquired with Springer collaboration.

\section{E-Publishing}

Authors had to wait for 9-12 months before a Research paper or Short communication could be published in Indian Pediatrics, from the date of acceptance; because of heavy backlog due to increased quantum of submissions and limited printing space. To obviate this problem, Indian Pediatrics started to electronically publish all accepted articles much before the print version (E-pub ahead of print), and also provide an immediate link to PubMed. The paper is thus available in public domain and to the scientific fraternity almost as soon as it is accepted.

\section{Supplement, Special Issues and BоOKS}

Indian Pediatrics brought out a supplement issue on "Child QSpringer $\begin{aligned} & \text { Development" in January 2009, } \\ & \text { based on the work done at Child }\end{aligned}$
Development
Centre, QSpringer $\begin{aligned} & \text { Development" in January 2009, } \\ & \text { based on the work done at Child }\end{aligned}$
Development
Centre, פSpringer $\begin{aligned} & \text { Development" in January 2009, } \\ & \text { based on the work done at Child }\end{aligned}$
Development
Centre, Thiruvananthapuram, Kerala. UNICEF supported two
Special Issues on (a) Immunization with Special Focus 
on Measles (2009) and (b) severe acute malnutrition (2010). MCH-Star, USAID and INCLEN supported release of another special issue on "ARI and Tuberculosis" (January 2010). Another feather in the cap of Indian Pediatrics was the publication of all guidelines and recommendations formulated by the Indian Academy of Pediatrics (IAP), its Chapters, Groups, and Committees; and other National bodies, in the form of a book entitled "Editors choice: The Best of Indian Pediatrics for the Practitioners," released in 2009. The entire print order was sold in 2 years. We also released the 3rd edition of Textbook on Pediatric and Neonatal Emergencies in December 2010, a much sought after publication by both practitioners and students of Pediatrics [4].

\section{Workshops on Art and Science of Paper Writing}

To encourage young faculty and train them in reporting research findings, Indian Pediatrics initiated the workshops on 'Art \& Science of Paper Writing.' The journal has successfully conducted eight such workshops till date. In 2011, three workshops were conducted under presidential plan at Kottayam, Delhi and Bangalore. Another workshop was conducted at Institute of Medical Sciences, BHU, Varanasi. The $8^{\text {th }}$ Workshop on Art and Science of Paper Writing was held in Delhi on 11-12 August, 2012 and next workshop is planned at Karamsad, Gujarat in February 2013. All these workshops received overwhelming response and excellent feedback from participants [4].

\section{Golden Jubilee Volume 2013}

The Golden Jubilee Commemorative issue is in your hands. We have tried to put in a judicious mix of history, politics, academics, administration, and science rolled in a single issue. Section "Journey over the Years" will continue throughout the year. By the time you receive this issue, it would have been released by His Excellency Dr. APJ Abdul Kalam, Ex-President of India, in Pedicon 2013 at Kolkata. We hope that you will like the new cover and contents of the Golden Jubilee issue. Any comments, suggestions, and criticisms are welcome.

They say that a job well-started is half the work done. Well, we seem to have started alright. But here ends the beginning! What lies ahead is the other half (or maybe, even more) of a long, tough road.

Enjoy reading!

Piyush Gupta Editor-in-Chief, Indian Pediatrics (2008-2013). prof.piyush.gupta@gmail.com

\section{REFERENCES}

1. Gupta P. Choudhury P. Impact factor and Indian Pediatrics. Indian Pediatr.2006;43:107-10.

2. Gupta P. Indian Pediatrics: Looking ahead. Indian Pediatr. 2008;45:9-10.

3. Gupta P, Shah D. Another feather in the cap: launch of international edition and activation of online manuscript management system. Indian Pediatr. 2010;47:559-60.

4. Gupta P, Mishra D. Impact factor 2011 and random musings. Indian Pediatr. 2012;49:609.

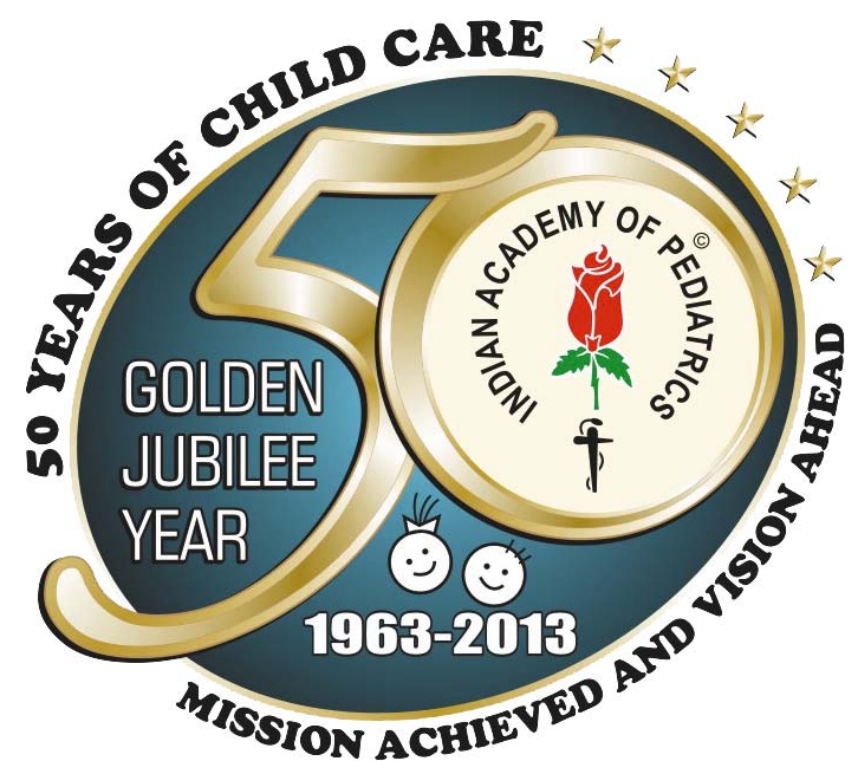

INDIAN PEDIATRICS 